\title{
Prevalence of Overweight, Obesity and Abdominal Obesity among the Adult Population of Yakutia
}

\author{
E.S. Kylbanova, N.V. Borisova*, T.M. Klimova, V.N. Neustroeva, E.P. Borisova, S.V. Markova, \\ S.S. Sleptsova, I. Sh. Malogulova, U. S. Portnyagina, A.A. Donskaya, P.G. Petrova, N.M. Gogolev \\ North-Eastern Federal University named after MK Ammosov \\ Yakutsk, the Republic of Sakha (Yakutia), Yakutsk, the Russian Federation
}

\begin{abstract}
This study describes data obtained as a result of a one-stage epidemiological study for levels of CVD risk factors among indigenous and non-indigenous populations of the Republic of Sakha (Yakutia) (RS(Y)).

A total of 1,856 indigenous residents (Yakuts) and non-indigenous residents (Russians) were examined: 512 men (mean

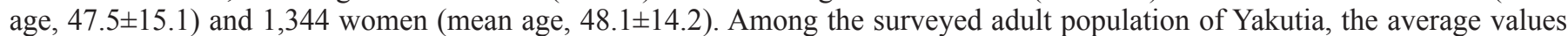
of BMI, regardless of ethnicity, were high with a regular increase in this indicator with age, especially in women. Overweight is more common for indigenous men (40\%) compared with indigenous women (34.5\%). Among the non-indigenous residents, there were no gender differences. In the sample of the indigenous population, obesity was more common in women $(24.3 \%)$ than in men (18.7\%). Among non-indigenous residents, similar differences were not obtained, except for a higher incidence of obesity in older women. The average waist circumference in men and women of both ethnic groups is not high, but the indicators are higher for men than for women; the gender differences are leveled in the older age group in both ethnic groups. Prevalence of abdominal obesity (AO) is extremely high in indigenous residents (61.6\%); in both ethnic groups, the prevalence of AO is higher among women than men. The incidence of overweight, obesity and AO was significantly higher in Yakut people.(International Journal of Biomedicine. 2017;7(4):319-323.)
\end{abstract}

Key Words: overweight $\bullet$ obesity $\bullet$ abdominal obesity $\bullet$ metabolic syndrome

\section{Abbreviations}

AO, abdominal obesity; BW, body weight; BMI, body mass index; CVD, cardiovascular diseases; HC, hip circumference; MS, metabolic syndrome; WC, waist circumference.

\section{Introduction}

Throughout the world, especially in developed countries, obesity, having a non-infectious pandemic character, has become a major health problem. According to the WHO $39 \%$ of adults aged 18 years and over were overweight in 2016, and $13 \%$ were obese. ${ }^{(1)}$ The proportion of obese men and women in Europe ranges from $10 \%$ to $20 \%$ and from $15 \%$ to $25 \%$, respectively. In Russia, more than $60 \%$ of the adult population suffer from being overweight and about

*Corresponding author: Natalia V. Borisova, PhD, ScD. Medical Institute of North-Eastern Federal University named after MK Ammosov Yakutsk, the Russian Federation.

E-mail: mira44@mail.ru
$26 \%$ from obesity. Life expectancy in morbid obesity is reduced by 9 years for women and by 12 years for men. ${ }^{(1,2)}$

An increase in BMI leads to an increase in the risk of developing concomitant diseases. The risk of complications, especially cardiovascular and metabolic, depends not only on the degree of obesity, but also on its type (localization of fatty deposits). The most unfavorable to health and most common for men is $\mathrm{AO}$, when fat is deposited between internal organs in the waist region. ${ }^{(3)}$

The role of overweight and obesity in the development of CVD is not clearly established at this time. In studies, different criteria for obesity are often used, and therefore reports of CVD and obesity are contradictory. ${ }^{(3)}$ At the same time, obesity increases the development and progression of such conditions as hypertension, diabetes mellitus, dyslipidemia, and MS. In 
addition, obesity is an easily determined marker of risk.

For all the variety of reasons leading to the development of the main manifestations of MS, of primary importance in its pathogenesis is irrational nutrition. Nutrition is one of the main factors determining the health of the population; on the one hand, nutrition can act as a disease prevention tool, and on the other, as an etiological factor or risk factor for many common chronic, noncommunicable diseases. ${ }^{(4,5)}$

In the past two decades, interest in the study of the physical status of humans in the North has increased. ${ }^{(6-10)}$ Numerous data confirm the presence of morphofunctional features in the indigenous people of the North that can be considered as a product of a long evolution and adaptation of humans to unfavorable conditions of existence. ${ }^{(8,9,11)}$

The aim of our study was to estimate the prevalence of overweight and obesity, including AO, among the indigenous and non-indigenous residents of Yakutia.

\section{Materials and Methods}

The Republic of Sakha (Yakutia) (RS(Y)) is the largest subject of the Russian Federation. About $40 \%$ of the territory of Yakutia lies above the Arctic Circle. Limiting factors for the human body in the extreme conditions of Yakutia are both climatic and man-made. ${ }^{(12)}$ The study was carried out within the framework of the project "Multifactor study of the health status of the indigenous and non-indigenous populations of $\mathrm{RS}(\mathrm{Y})$ aimed to optimize the regional programs for improving the quality of life of the inhabitants of the republic, taking into account the territorial and ethnic characteristics in the context of modern socioeconomic development" (State Project No. 6512 of September 6, 2017). The study protocol was reviewed and approved by the Ethics Committee of North-Eastern Federal University named after MK Ammosov. All participants provided the written informed consent.

A total of 1,856 indigenous residents (Yakuts) and non-indigenous residents (Russians) were examined: 512 men (mean age, 47.5 \pm 15.1 ) and 1,344 women (mean age, 48.1 \pm 14.2 ). The surveyed respondents were divided into 2 age groups: Group 1, between 18 and 59 years, and Group 2 , over 60 years.

The survey program included a comprehensive exam with a developed map questionnaire. The questionnaire consisted of several sections: socio-demographic, anamnestic data, heredity, physical activity, bad habits, and anthropometry.

The methods of basic screening and facultative studies were standardized and carried out in accordance with the recommendations adopted for epidemiological studies. The length of the body was measured with a digital anthropometry device, Tanita, and a digital anthropometry device, Martin, during the expedition surveys, with an accuracy of $0.1 \mathrm{~cm}$. BW was measured without clothing using medical scales with an accuracy of $50 \mathrm{~g}$. WC and HC were measured with a centimeter tape with an accuracy of $0.1 \mathrm{~cm}$. BMI is calculated using Quetelet's formula:

BMI = body weight $(\mathrm{kg}) /$ height $(\mathrm{cm})^{2}$

BMI value between $25 \mathrm{~kg} / \mathrm{m}^{2}$ and $30 \mathrm{~kg} / \mathrm{m}^{2}$ was assessed as overweight, BMI value above $30 \mathrm{~kg} / \mathrm{m}^{2}$ was assessed as obesity.
WC was measured in the smallest circle, below the rib cage and above the navel; HC was measured at the buttock level, where there is the greatest circumference. According to the NCEP ATP III definition (2001), AO is defined as WC > $102 \mathrm{~cm}$ for men and $>88 \mathrm{~cm}$ for women.

Statistical analysis was performed using statistical software package SPSS v. 19.0. Baseline characteristics were summarized as frequencies and percentages for categorical variables and as means and SDs for continuous variables. Analysis of the distribution of values obtained was performed using the Kolmogorov-Smirnov test. For data with normal distribution, inter-group comparisons were performed using Student's t-test. The Mann-Whitney U Test was used to compare the differences between the two independent groups (for nonparametric data). Categorical variables were analyzed using the Chi-square test. A probability value of $\mathrm{P}<0.05$ was considered statistically significant.

\section{Results and Discussion}

The obtained data from anthropometric studies are presented in Table 1. The average BMI among the indigenous residents of Yakutia was high and amounted to $26.7 \pm 5.13 \mathrm{~kg} / \mathrm{m}^{2}$. With age, this indicator increased in Group 2 for women. In men, such dynamics were not observed.

The average WC in indigenous residents of Yakutia was $88.4 \pm 13.6 \mathrm{~cm}$. This indicator was higher in men $(91.8 \pm 1282$ $\mathrm{cm})$ than in women $(87.2 \pm 13.65 \mathrm{~cm})$ with statistical significance in Group 1 (Table 1).

Table 1.

Anthropometric parameters of indigenous residents of Yakutia

\begin{tabular}{|c|c|c|c|c|}
\hline Group & Total & Men & Women & $\mathrm{P}$ \\
\hline \multicolumn{5}{|c|}{ BMI $\left(\mathrm{kg} / \mathrm{m}^{2}\right)$} \\
\hline Total & $26.7 \pm 5.13$ & $26.5 \pm 4.61$ & $26.8 \pm 5.31$ & 0.502 \\
\hline Group 1 & $26.6 \pm 5.17$ & $26.5 \pm 4.71$ & $26.6 \pm 5.32$ & 0.967 \\
\hline Group 2 & $27.2 \pm 4.98$ & $26.6 \pm 4.32$ & $27.4 \pm 5.21$ & 0.08 \\
\hline$P_{1-2}$ & $<0.01$ & 0.545 & $<0.01$ & \\
\hline \multicolumn{5}{|c|}{$\mathrm{WC}(\mathrm{cm})$} \\
\hline Total & $88.4 \pm 13.58$ & $91.8 \pm 12.82$ & $87.2 \pm 13.65$ & $<0.001$ \\
\hline Group 1 & $87.5 \pm 13.40$ & $91.6 \pm 13.33$ & $86.1 \pm 13.12$ & $<0.001$ \\
\hline Group 2 & $91.5 \pm 13.72$ & $92.5 \pm 11.34$ & $90.9 \pm 14.55$ & 0.214 \\
\hline$P_{1-2}$ & $<0.001$ & 0.194 & $<0.001$ & \\
\hline
\end{tabular}

In indigenous residents, $36 \%$ of cases were found to be overweight and $22.9 \%$ were obese (Table 2). We identified the gender differences in the prevalence of overweight and obesity. In males, the frequency of overweight was higher than in women ( $40 \%$ vs. $34.5 \%$, respectively), but obesity, on the contrary, was more common for women $(24.3 \%)$ than for men $(18.7 \%)$. These differences were more pronounced in Group 2. With age, an increase in the frequency of overweight was found only for men; obesity did not differ significantly 
in men and women (Table 2). Similar data were obtained by T.Klimova and colleagues ${ }^{(6)}$ for the indigenous rural population of Yakutia. According to the BMI categories, they found low BW in $2 \%$ of men and women; normal BW in $44 \%$ of men and $38 \%$ of women; pre-obesity in $37 \%$ and $34 \%$, respectively; and obesity in $18 \%$ and $26 \%$, respectively.

\section{Table 2.}

Prevalence of overweight and obesity (by BMI) and AO among the indigenous population of Yakutia

\begin{tabular}{|c|c|c|c|c|}
\hline Group & Total & Men & Women & $\mathrm{P}$ \\
\hline \multicolumn{5}{|c|}{ Overweight } \\
\hline Total & 36.0 & 40.0 & 34.5 & $<0.05$ \\
\hline Group 1 & 34.5 & 37.0 & 33.6 & 0.246 \\
\hline Group 2 & 41.2 & 49.6 & 38.0 & $<0.05$ \\
\hline$P_{1-2}$ & $<0.05$ & $<0.05$ & 0.164 & \\
\hline \multicolumn{5}{|c|}{ Obesity } \\
\hline Total & 22.9 & 18.7 & 24.3 & $<0.05$ \\
\hline Group 1 & 22.5 & 20.2 & 23.4 & 0.211 \\
\hline Group 2 & 24.0 & 14.2 & 27.8 & $<0.01$ \\
\hline$P_{1-2}$ & 0.533 & 0.154 & 0.123 & \\
\hline \multicolumn{5}{|c|}{$\mathrm{AO}$} \\
\hline Total & 61.6 & 42.0 & 68.5 & $<0.001$ \\
\hline Group 1 & 58.8 & 39.9 & 65.5 & $<0.001$ \\
\hline Group 2 & 70.8 & 48.5 & 78.8 & $<0.001$ \\
\hline$P_{1-2}$ & $<0.001$ & 0.130 & $<0.001$ & \\
\hline
\end{tabular}

The prevalence of $\mathrm{AO}$ among indigenous residents of Yakutia was extremely high (61.6\%): $42 \%$ for men and $68.5 \%$ for women.(Table 2) A significant excess of AO in women compared with men persisted in the analysis by age group. In women, the increase in the frequency of $\mathrm{AO}$ with age was more pronounced than in men $(79 \%$ among women of Group 2 ), which influenced the high incidence of $\mathrm{AO}$ in the general population. According to T.Klimova et al., the prevalence of AO (by IDF criteria) among the rural indigenous population of Yakutia was also high: $34 \%$ for men and $62 \%$ for women. ${ }^{(6)}$

The results of studies in the North that evaluate the fat component of the body, provide the distinctive anthropometric features in indigenous inhabitants: 1) Distribution of fat is almost the same for all age groups with the greatest manifestation in the abdomen, chest, back and shoulder, regardless of age; 2) The average number of skin fat folds of the shoulder (the front and back surfaces), forearm, abdomen, hip, and lower leg was significantly higher in middle-aged men than in older men; 3 ) The age-related changes in BW of women are associated with the development of the predominantly fat component in the abdomen, with pronounced age differences. ${ }^{(6-9)}$ The results of the research show that the indigenous northern populations, in the process of adaptation to extreme climatic conditions, developed the specific features of their constitution (high body density, stocky physique with well-developed musculoskeletal mass), which were aimed to slow heat transfer. The rural population of Yakutia is characterized by typical features inherent in the northern adaptive type - small body length with relatively large mass, WC and $\mathrm{HC}$, and a favorable lipid spectrum. ${ }^{(6)}$

It has been established that the indigenous population of the Far North is characterized by a protein-lipid type of nutrition, which contributes to the formation of the "polar metabolic type." ${ }^{(13-15)}$ In recent years, the change in the lifestyle of the indigenous people has led to a change in the traditional diet. A few studies on the features of the actual diet of the Yakut population revealed that the diet of the elderly is unbalanced in fat and carbohydrate components: a high proportion of total fat intake, including saturated fat. A high content of refined sugars was noted against a background of a low intake of complex carbohydrates, dietary fiber, both in the Yakut and Caucasian ethnic groups. ${ }^{(16)}$ Thus, an analysis of the current trends in nutrition of people 60 years of age and over in Yakutia, with an assessment of the impact of these dietary habits in the formation of overweight, obesity, and AO indicates a high prevalence of these factors in the population.

In the non-indigenous population of Yakutia, mean BMI was not significantly different between males and females of Group 1 (Table 3).

Table 3.

Anthropometric parameters of non-indigenous residents of Yakutia

\begin{tabular}{|c|c|c|c|c|}
\hline Group & Total & Men & Women & $\mathrm{P}$ \\
\hline \multicolumn{5}{|c|}{$\operatorname{BMI}\left(\mathrm{kg} / \mathrm{m}^{2}\right)$} \\
\hline Total & $25.4 \pm 5.1$ & $25.47 \pm 4.1$ & $25.46 \pm 5.5$ & 0.963 \\
\hline Group 1 & $25.1 \pm 4.8$ & $25.38 \pm 4.2$ & $24.93 \pm 5.2$ & 0.236 \\
\hline Group 2 & $29.7 \pm 5.6$ & $26.72 \pm 2.9$ & $30.61 \pm 6.0$ & $<0.01$ \\
\hline$P_{1-2}$ & $<0.001$ & 0.182 & $<0.001$ & \\
\hline \multicolumn{5}{|c|}{$\mathrm{WC}(\mathrm{cm})$} \\
\hline Total & $81.6 \pm 13.7$ & $86.18 \pm 12.7$ & $79.28 \pm 13.6$ & $<0.001$ \\
\hline Group 1 & $80.4 \pm 13.0$ & $85.74 \pm 12.7$ & $77.69 \pm 12.4$ & $<0.001$ \\
\hline Group 2 & $94.3 \pm 14.3$ & $92.67 \pm 11.2$ & $94.83 \pm 15.3$ & 0.583 \\
\hline$P_{1-2}$ & $<0.001$ & $<0.05$ & $<0.001$ & \\
\hline
\end{tabular}

In Group 2, the mean BMI was significantly higher in females than in males, as in the indigenous population of Yakutia; however, these differences were leveled in the older age group (Table 3). With age, both in the group of men and women, the mean values of WC increased.

In the non-indigenous population, $31.1 \%$ of cases were found to be overweight and $16.2 \%$ were obese (Table 4 ). We found gender- and age-related differences in the prevalence of obesity. In Group 2, obesity was found in $47.2 \%$ of nonindigenous women and in $16.7 \%$ non-indigenous men $(\mathrm{P}<0.05)$. The incidence of $\mathrm{AO}$ was significantly higher in women than in men, regardless of age.

A comparative analysis of the BMI values revealed a high prevalence of overweight and obesity among the 
indigenous residents of Yakutia. The prevalence of AO among these residents was also about 2 times higher than in nonindigenous residents (Table 5).

Table 4.

Prevalence of overweight and obesity (by BMI) and $A O$ among the non- indigenous population of Yakutia

\begin{tabular}{|c|c|c|c|c|}
\hline Group & Total & Men & Women & $\mathrm{P}$ \\
\hline \multicolumn{5}{|c|}{ Overweight } \\
\hline Total & 31.1 & 35.1 & 29.1 & 0.076 \\
\hline Group 1 & 30.1 & 33.7 & 28.2 & 0.115 \\
\hline Group 2 & 42.3 & 55.6 & 37.7 & 0.186 \\
\hline$P_{1-2}$ & $<0.05$ & 0.060 & 0.147 & \\
\hline \multicolumn{5}{|c|}{ Obesity } \\
\hline Total & 16.2 & 13.8 & 17.4 & 0.187 \\
\hline Group 1 & 14.1 & 13.6 & 14.3 & 0.797 \\
\hline Group 2 & 39.4 & 16.7 & 47.2 & $<0.05$ \\
\hline$P_{1-2}$ & $<0.001$ & 0.719 & $<0.001$ & \\
\hline \multicolumn{5}{|c|}{$\mathrm{AO}$} \\
\hline Total & 36.7 & 24.1 & 43.0 & $<0.001$ \\
\hline Group 1 & 32.9 & 22.7 & 38.1 & $<0.001$ \\
\hline Group 2 & 78.9 & 44.4 & 90.6 & $<0.001$ \\
\hline$P_{1-2}$ & $<0.001$ & $<0.05$ & $<0.001$ & \\
\hline
\end{tabular}

Table 5.

Prevalence of overweight and obesity (by BMI) and $A O$ among the indigenous and non- indigenous populations of Yakutia

\begin{tabular}{|l|c|c|c|c|}
\hline \multicolumn{1}{|c|}{ Variable } & Total & Indigenous & Non-indigenous & $\mathrm{P}$ \\
\hline Overweight & 34.6 & 36.0 & 31.7 & $<0.05$ \\
\hline Obesity & 20.7 & 22.9 & 16.4 & $<0.001$ \\
\hline AO & 53.0 & 61.6 & 37.4 & $<0.001$ \\
\hline
\end{tabular}

Thus, the high level of metabolic risk factors (high prevalence of overweight, obesity and abdominal obesity) in Yakuts suggests the cause lies in the dietary imbalance ${ }^{(16)}$ and allows predicting negative trends in the development of metabolic disorders with an increase in the prevalence of MS.

\section{Conclusion}

1. Among the surveyed adult population of Yakutia, the average values of BMI, regardless of ethnicity, were high with a regular increase in this indicator with age, especially in women.

2. Overweight is more common for indigenous men (40\%) compared with indigenous women (34.5\%). Among the non-indigenous residents, there were no gender differences. In the sample of the indigenous population, obesity was more common in women $(24.3 \%)$ than in men (18.7\%). Among nonindigenous residents, similar differences were not obtained, except for a higher incidence of obesity in older women.
3. The average WC in men and women of both ethnic groups is not high, but the indicators are higher for men than for women; the gender differences are leveled in the older age group in both ethnic groups.

4. Prevalence of AO is extremely high in indigenous residents $(61.6 \%)$; in both ethnic groups, the prevalence of $\mathrm{AO}$ is higher among women than men.

5. The incidence of overweight, obesity and AO was significantly higher in Yakut people.

\section{Competing interests}

The authors declare that they have no competing interests.

\section{Sources of Funding}

The study was carried out within the framework of the project "Multifactor study of the health status of the indigenous and non-indigenous populations of RS(Y) aimed to optimize the regional programs for improving the quality of life of the inhabitants of the republic, taking into account the territorial and ethnic characteristics in the context of modern socioeconomic development" (State Project No. 6512 of September 6, 2017).

\section{References}

1. WHO. Obesity and overweight. Fact sheet. Updated October 2017. Available from: http://www.who.int/ mediacentre/factsheets/fs311/en/

2. Ashwell M. The health of the nation target for obesity. Int J Obes. 1994; 18: 837-840.

3. Diagnosis and correction of lipid metabolism disorders in order to prevent and treat atherosclerosis. Brief version of the Russian recommendations v.6. Moscow, 2017. [in Russian]. 4. Medvedeva IV, Dorodneva EF, Pugacheva TA. Nutrition in the pathogenesis, treatment and prevention of metabolic syndrome. Tyumen: Publishing Center "Academy"; 2004. [in Russian].

5. Viskunova AA, Kaganov BS, Sharafetdinov KhKh, Plotnikova OA. [Role of alimentary factor in correction of the main features of the metabolic syndrome. Modern approaches to dietary]. Vopr Pitan. 2009;78(5):4-10. [Article in Russian]. 6. Klimova TM, Fedorova VI, Baltahinov ME. [Obesity criteria for identification of metabolic risk factors among indigenous rural population of Yakutia]. Siberian Medical Journal (Irkutsk). 2012;8:110-113. [Article in Russian].

7. Koinosov PG, Chiryatyeva TV, Sokolov AG, Tolstikova NV. [Somatotypologic features of growth and development of children's organism in the North]. Biomed Biosos Anthropol. 2004;2:29-30. [Article in Russian].

8. Orekhov KV, Prahin EI. [The tendency of physical development in ontogeny in the Far North conditions]. The Bulletin of Siberian Branch of Academy of Medical Sciences of the USSR. 1986;2:3-8. [Article in Russian].

9. Pashkova IG, Aleksina LA. [Ontogenetic changes in the physical status of women in the Republic of Karelia]. Uchenye zapiski SPbMU im. akad. I.P. Pavlov. 2011; XVIII(1):36-39. [Article in Russian]. 
10. Petrova PG, Borisova NV, Kylbanova ES. [Analysis of the main risk factors for cardiovascular diseases among residents of the Western economic zone (by the example of the Nyurba district)]. Bulletin of the NEFU. Series "Medical Sciences". 2017;3(08):23-30. [Article in Russian].

11. Guryeva AB. [Age features of body proportions of Yakut women in the Republic Sakha (Yakutia)]. Yakut Medical Journal. 2015;2(50):90-92. [Article in Russian].

12. Borisova NV, Markova SV, Petrova PG. Imbalance of Macro- and Micronutrients in the Environment and Biosubstrates of Residents Living in the Diamond Mining Region of Yakutia. IJBM. 2014;4(3):179-181.
13. Recommendations of the experts of the VNOK for the diagnosis and treatment of metabolic syndrome. The second revision. Moscow, 2009. [in Russian].

14. Fonseca V. Metabolic syndrome. Trans. from English. Moscow: "Practice", 2011. [in Russian].

15. Boden G. Obesity, insulin resistance, Type 2 diabetes and free fat acids. Expert Rev Endocrinol Metab. 2006;4(1):499-505.

16. Neustroeva VN, Simonova GI, Kylbanova ES, Tatarinova OV, Shcherbakova LV, Veryovkin EG. [Actual nutrition character of an elderly and senile population in Yakutsk with a metabolic syndrome]. Vestnik of North-Eastern Federal University. 2013;10(2):127-133. [Article in Russian]. 